Cahiers d'études africaines

$229 \mid 2018$

Varia

\title{
23e Rencontre biennale de la Society of Africanist Archaeologists
}

\section{Thomas Soubira}

\section{(2) OpenEdition}

12 Journals

Édition électronique

URL : https://journals.openedition.org/etudesafricaines/22050

DOI : 10.4000/etudesafricaines.22050

ISSN : $1777-5353$

Éditeur

Éditions de l'EHESS

\section{Édition imprimée}

Date de publication : 15 mars 2018

Pagination : 268-270

ISBN : 978-2-7132-2741-7

ISSN : 0008-0055

Référence électronique

Thomas Soubira, "23e Rencontre biennale de la Society of Africanist Archaeologists », Cahiers d'études africaines [En ligne], 229 | 2018, mis en ligne le 15 mars 2018, consulté le 21 avril 2022. URL http://journals.openedition.org/etudesafricaines/22050 ; DOl : https://doi.org/10.4000/ etudesafricaines.22050

Ce document a été généré automatiquement le 21 avril 2022.

(c) Cahiers d'Études africaines 


\title{
23e Rencontre biennale de la Society of Africanist Archaeologists
}

\author{
Thomas Soubira
}

\section{RÉFÉRENCE}

$23^{e}$ e Rencontre biennale de la Society of Africanist Archaeologists (SAfA), TRACES

(Université de Toulouse-Jean Jaurès), Musée royal de l'Afrique centrale (Tervuren, Belgique), Laboratoire Archéologie et Peuplement de l'Afrique (Université de Genève, Suisse), 26 juin-2 juillet 2016, Université de Toulouse-Jean Jaurès.

1 Suite à l'édition 2014 qui s'était tenue à l'Université de Witwatersrand en Afrique du Sud, jumelée à cette occasion avec le congrès de la PanAfrican Archaeological Association, la $23^{\mathrm{e}}$ Rencontre biennale de la Society of Africanist Archaeologists s'est déroulée du 26 juin au 2 juillet 2016 à Toulouse, une première sur le territoire français. L'événement était organisé conjointement par le laboratoire TRACES (Université de Toulouse-Jean Jaurès), le Musée royal de l'Afrique centrale (Tervuren, Belgique) et le Laboratoire Archéologie et Peuplement de l'Afrique (Université de Genève, Suisse), des institutions européennes parmi les plus dynamiques en terme de recherche archéologique sur le continent africain. En quelques chiffres, l'édition 2016 de la SAfA a réuni près de 500 communicants spécialistes d'archéologie africaine (étudiants de master, doctorants, chercheurs confirmés) venus d'une soixantaine de pays pour discuter de leurs recherches récentes par le biais de 41 sessions thématiques. Les congressistes ont également pu échanger, au moment des pauses, devant les 85 posters inédits ou complémentaires des interventions orales.

2 Un très large spectre chronologique a été employé pour répondre à la question générale soulevée par ce congrès, « quels passés pour l'Afrique ? ", illustrant la richesse et la diversité scientifique que peuvent offrir les terrains africains, avec en particulier un point d'honneur apporté à la Préhistoire, la période la plus largement représentée $\mathrm{du}$ nord au sud du continent. Certaines sessions ont remarquablement franchi la 
barrière chronologique pour, au final, pousser la réflexion sur un temps long, qu'il s'agisse de formation des paysages, de transrégionalisme ou de commerce transsaharien. D'un point de vue géographique, la majeure partie des régions africaines étaient représentées, de l'art rupestre du Maghreb jusqu'aux cultures matérielles du Middle Stone Age en Afrique australe, en passant par la néolithisation de la Corne de l'Afrique. Certains territoires ont bénéficié de sessions privilégiées comme le Nigéria, l'Ouganda ou le Sénégal ou encore les sites d'Aksum (emblème de la civilisation de l'Antiquité tardive) en Éthiopie et Gobero (site néolithique de référence au Sahara) au Niger. Plusieurs programmes pluridisciplinaires ont également été mis en avant. Citons, par exemple, le projet ERC Crossroads of Empires (dirigé par Anne C. Haour de l'Université d'East Anglia) dont les travaux sont venus clôturer plus de cinq années d'investigations dans la région du Dendi (Bénin). Plusieurs membres du programme franco-marocain d'étude du site médiéval oasien de Sijilmâsa (Maroc), programme dirigé par François-Xavier Fauvelle (par ailleurs, président du comité d'organisation de ce congrès), ont pu présenter les récents résultats archéologiques, géologiques, architecturaux et historiques dans plusieurs sessions dont celle intitulée «Islamic Archaeology and the Preservation of Muslim Heritage in Africa ", réunissant les principaux acteurs d'une discipline - l'archéologie islamique - bien souvent sousreprésentée dans les réunions scientifiques africanistes.

3 Au sens large, l'ensemble des sessions a proposé un vaste panel des recherches archéologiques récentes en Afrique, regroupées par disciplines (industries lithiques, géoarchéologie, métallurgie, anthropologie, archéozoologie, céramologie, archéologie spatiale, etc.) sans pour autant tomber dans le classicisme. Au contraire, en mettant en exergue le renouveau de l'archéologie africaine, grâce en particulier au développement depuis quelques années de disciplines jusqu'à présent minoritaires autour du paléoenvironnement, de la domestication des plantes et des régimes alimentaires, on a également pu mesurer, à la faveur de cet événement scientifique, les avancées de la connaissance. Celles-ci s'illustrent grâce à l'introduction et à la généralisation de nouvelles techniques de traitement des données comme l'application dans le domaine de l'archéozoologie d'outils analytiques employés hors d'Afrique ou encore la modélisation 3D, l'archéomagnétisme et la luminescence stimulée optiquement appliquées à la géoarchéologie. Au-delà du thème général interrogeant les " passés » de l'Afrique, et à travers la récurrence de certains thèmes tels que le patrimoine évoqué dans bon nombre de communications, les regards sont bien tournés sur l'avenir, qu'il s'agisse de la collecte des données sur le terrain ou de l'exploitation et de la mise en valeur de ces mêmes données, tant sur le territoire africain qu'à travers le monde. Ainsi, l'une des nouveautés de cette année a été une session (coordonnée par Els Cornelissen) entièrement consacrée à la muséographie et aux archives de l'archéologie. D'ailleurs, face à la multiplication des travaux d'infrastructure de grande envergure sur le continent africain, une session bénéfique et novatrice dédiée à l'archéologie préventive a révélé le recours nécessaire aux interventions archéologiques sur les modèles occidentaux, en amont ou en parallèle des aménagements, dans le but de préserver ces patrimoines nationaux, avec les exemples du Cameroun, du Ghana ou de la Côte d'Ivoire, s'inspirant notamment du modèle français de l'INRAP. Enfin, l'émergence de la recherche concernant l'esclavage transatlantique et son empreinte archéologique en Afrique demeure l'un des faits marquants de ce congrès, que l'on retrouvera très certainement au cours des éditions futures. 
4 Comme à chaque édition, des excursions sont organisées pour les congressistes afin de découvrir le patrimoine régional. Cette année, en dehors des déambulations libres dans la très belle ville de Toulouse, les organisateurs ont proposé aux africanistes un voyage au cœur du Paléolithique supérieur pyrénéen avec les visites des incontournables grottes ornées de Gargas, Niaux, et Pech Merle, du chantier archéologique en cours de la grotte du Mas d'Azil ainsi que du nouveau et moderne Musée Forum de l'Aurignacien. Les participants ont également pu admirer la splendeur de l'architecture médiévale du sud de la France avec les visites de la fameuse cité de Carcassonne et de la cité épiscopale d'Albi. Le dîner de gala clôturant le congrès s'est tenu dans le superbe château de Laréole du XVI ${ }^{\mathrm{e}}$ siècle, à l'architecture vernaculaire de briques rouges et de pierres. La prochaine rencontre de la SAfA se tiendra du 18 au 21 juin 2018 sur le continent américain, à l'Université de Toronto au Canada. 